\title{
Связь ценностной структуры и субъективного экологического
}

\section{благополучия личности}

(C) 2021 Хащенко Надежда Николаевна*, Баранова Анна Викторовна**, Панова Екатерина Михайловна ${ }^{* * *}$, Смирнова Нина Павловна ${ }^{* * * * *}$ *кандидат психологических наук, Институт психологии РАН, руководитель проекта НОЧУ ВО «Московский институт психоанализа», (г. Москва),e-mail:

\section{nadin-khash@yandex.ru}

***андидат психологических наук, исполнитель проекта НОЧУ ВО «Московский институт психоанализа», (г. Москва), e-mail:

\section{anna_baranova80@mail.ru}

**** исполнитель проекта НОЧУ ВО «Московский институт психоанализа», (г. Москва), e-mail: panova098@mail.ru ***** кандидат психологических наук, исполнитель проекта НОЧУ ВО «Московский институт психоанализа», (г. Москва), e-mail: npsmir@mail.ru

Исследование выполнено при финансовой поддержке РФФИ, проект № 19-01300832 («Экологическое благополучие в ценностной структуре личности во взаимосвязи с ее экономико-психологическими характеристиками»)

Аннотация: Представлены результаты эмпирического исследования связи субъективного экологического благополучия личности и его компонентов с индивидуальными базовыми ценностями личности. Определены ценностные предикторы (индивидуальные базовые ценности) субъективного экологического благополучия личности. Субъективное экологическое благополучие личности определяют противоположные «ценности высшего порядка» - «Самопреодоления» и «Самоутверждения», «Открытости 
изменениям» и «Сохранения». С позиции метаценностей (по Ш.Шварцу), субъективное экологическое благополучие личности в большей степени зависит от ценностей, имеющих социальную направленность, они связаны с другими людьми и устоявшимися институтами, выражают интересы группы.

Ключевые слова: субъективное экологическое благополучие, ценностная структура, индивидуальные базовые ценности

The relationship between the value structure and the subjective ecological well-being of the individual

(C) 2021 Khashchenko Nadezhda Nikolaevna*, Baranova Anna Viktorovna**, Panova Ekaterina Mikhailovna***, Smirnova Nina Pavlovna****

"Ph.D. (psychology), Institute of Psychology RAS, project head NOCHU VO

"Moscow Institute of psychoanalysis", (Moscow, Russia); e-mail: nadinkhash@yandex.ru

**Ph.D. (psychology), project executor NOCHU VO "Moscow Institute of psychoanalysis", (Moscow, Russia); e-mail: anna baranova80@mail.ru **** project executor NOCHU VO "Moscow Institute of psychoanalysis", (Moscow, Russia); e-mail: panova098@mail.ru

*****Ph.D. (psychology), project executor NOCHU VO "Moscow Institute of psychoanalysis", (Moscow, Russia); e-mail: npsmir@mail.ru

Annotation: The article presents the results of an empirical study of the relationship between the subjective ecological well-being of the individual and its components with the individual basic values of the individual. The value predictors (individual basic values) of the subjective ecological well-being of the individual have been determined. The subjective ecological well-being of an individual is determined by the opposite "values of the highest order" - "Self-overcoming" and "Self-affirmation", "Openness to change" and "Preservation". From the point of view of meta-values (according to Sh. Schwartz), the subjective ecological well-being of 
an individual is more dependent on values that have a social orientation, they are connected with other people and established institutions, and express the interests of the group.

Keywords: subjective environmental well-being, value structure, individual basic values

Актуальность изучения взаимоотношений человека и окружающей его природной среды обусловлены продолжающимся глобальным экологическим кризисом. Прогнозирование отношения личности и различных социальных групп к изменяющимся экологическим, социально-экономическим и другим условиям жизни в нашем обществе остается важной проблемой. Поведение человека, его ценности, потребности, субъективные переживания и т.п. определяются значимыми для личности аспектами ее жизнедеятельности. Отношение человека к экологическим условиям жизни, основанием его взаимодействия с окружающей природной средой выступает субъективное экологическое благополучие. С экологическим благополучием связывают степень осведомленности и понимания человеком решающей роли окружающей среды в его индивидуальном благополучии, осмысление того, что люди являются частью окружающей среды, что последствия деятельности человека всегда отражаются на окружающей его среде. Субъективное экологическое благополучие во многом определяется экологическим сознанием личности. Исследования экологического сознания как социальнопсихологического феномена и, в частности, актуального экологического сознания [Панов и др., 2012], выступают как отдельное направление психологии экологического сознания, вносящее свой вклад в развитие проблемы. Таким образом, согласно теоретическим представлениям, лежащим в основе исследования, субъективное экологическое благополучие личности характеризуется ее отношением к экологическим условиям жизни, т.е. ее актуальным экологическим сознанием, под которым понимается совокупность 
элементов экологического сознания, которые становятся ведущими, значимыми и определяют жизнедеятельность личности в различных условиях проживания. Субъективное экологическое благополучие, включено в систему жизненных целей личности [Хащенко, 2017]. В свою очередь, жизненные цели и отношение человека к себе, другим людям, явлениям окружающего мира определяются ее ценностными приоритетами, которые в рамках направленности личности создают основу мировоззрения, мотивационной активности, жизненной концепции в целом. Ценностные ориентации, как способ дифференциации индивидом объектов по их значимости, направляют поведение человека, определяют развитие личности, ее интересы, выбор жизненного пути, самоопределение человека, актуализируя его потенциал в будущем.

Целью данного эмпирического исследования выступило определение ценностных предикторов субъективного экологического благополучия личности. В процессе исследования решались следующие задачи:

- выделение компонентов субъективного экологического благополучия личности;

- установление выраженности индивидуальных базовых ценностей личности в «Ценностном портрете личности» (по Ш. Шварцу);

- соотнесение компонентов субъективного экологического благополучия личности и индивидуальных базовых ценностей личности, как предикторов отношения человека к экологическим условиям жизни.

Сбор эмпирических данных осуществлялся методом персонального формализованного интервью с помощью специально разработанной программы [Хащенко и др., 2020]. Все методики и методические приемы были объединены в формализованный опросник, большая часть данных получена через он-лайн опрос, с использованием «персонального» подхода к опрашиваемым (то есть отправляя опросник для заполнения, достигалась договоренность о согласии). 
C целью изучения ценностной составляющей субъективного экологического благополучия личности применялась методика Ш. Шварца, направленная на определение структуры базовых ценностей личности [Шварц и др., 2012]; шкала «Единение с природой» из Опросника экологического сознания, разработанного сотрудниками лаборатории экопсихологии развития ПИ РАО под руководством В.И. Панова, позволяющая судить о том, насколько человек ощущает себя частью природы и с чем связано данное переживание [Панов и др., 2012].

Для определения компонентов субъективного экологического благополучия личности анализировались основные характеристики и показатели актуального экологического сознания личности: удовлетворенность и динамика личностной оценки «благоприятности - неблагоприятности» экологической ситуации в районе проживания; значимость для личности экологических проблем, связанных с загрязнением природной среды; отношение личности к себе как субъекту экологического поведения; психологическая готовность личности к смене места жительства; значимость информированности и информированность личности о состоянии экологической ситуации в районе проживания; ценностное отношение личности к природе, связь и единение с природой, насколько человек ощущает себя частью природы и с чем связано данное переживание; беспокойство личности за собственное здоровье в связи с экологическими условиями проживания; психологическая напряженность личности из-за состояния здоровья членов семьи и близких в связи с экологическими условиями проживания.

\section{Результаты исследования и их интерпретация}

В процессе исследования с помощью метода факторного анализа были выделены компоненты субъективного экологического благополучия личности. Компоненты субъективного экологического благополучия были соотнесены с 
базовыми ценностями личности (по Ш. Шварцу), в результате регрессионного анализа определены ценностные предикторы каждого из компонентов.

Согласно представлениям Ш. Шварца, все индивидуальные ценности основываются на базовых условиях человеческого существования (одном или более): потребностях организма, стремлении к социальным взаимодействиям и потребности принадлежности к группе. При этом каждая ценность может быть описана через определенную мотивационную цель, к которой стремится человек в рамках значимой ценности.

Установлено, что первый компонент субъективного экологического благополучия, который мы условно обозначили как «Значимость благоприятности экологии», составляют вера в то, что со временем экологические условия жизни улучшатся, значимость благоприятности и отсутствие напряженности в связи с экологической ситуацией в районе проживания, при этом негативные оценки степени промышленного загрязнения в районе проживания и области; положительные оценки своего здоровья и относительной безопасности для здоровья экологической ситуации в регионе проживания, но обеспокоенность тем, что экологическая обстановка и может нанести вред здоровью. Ценностями, определяющими данный компонент выступили «Самостоятельность» (с отрицательным значением) и «Гедонизм» (табл.1).

Таблица 1.

Связь (зависимость) компонента «Значимость благоприятности экологии» субъективного экологического благополучия и ценностей личности $(\mathrm{N}=138)$.

\begin{tabular}{|c|c|c|c|c|}
\hline Компонент & Ценность & $\mathrm{b}^{*}$ & \multicolumn{2}{|c|}{ Мотивационная цель } \\
\hline Значимость & Самостоятельность &,- 525 & Свобода & развивать \\
\hline \multirow{2}{*}{ экологической } & & & собственные & идеи \\
\hline & & & способности, & определять \\
\hline ситуации & & & собственные д & гвия \\
\hline природы & Гедонизм &, 372 & Стремление к & вольствию и \\
\hline
\end{tabular}




\begin{tabular}{|l|l|l|l|}
\hline проживания & & & чувственному удовлетворению \\
\hline
\end{tabular}

Примечание: * - коэффициент регрессии, «0» в значениях перед запятой опущены.

Полученные данные свидетельствуют о том, что люди, склонные позитивно оценивать экологические условия проживания и их динамику от прошлого к будущему, кто не испытывает напряжения из-за экологических условий жизни при осознании того, что промышленные предприятия загрязняют окружающую среду и степень промышленного загрязнения в месте проживания оценивается как высокая, не стремятся к свободе развивать собственные идеи и способности, определять собственные действия. Для них более значимо получение удовольствия и чувственного удовлетворения как цель жизни.

Второй компонент субъективного экологического благополучия, обозначенный, как «Ответственность за экологию и природу в регионе проживания» определяется высокой степенью ответственности за состояние экологии в регионе проживания, которую возлагают, прежде всего на органы власти (президента, правительство, местные органы, органы охраны природы, руководство предприятий, а также политические партии и экологические движения), при этом личная ответственность не входит в данный конструкт.

Ценностными предикторами здесь выступают «Традиция», «Гедонизм», «Скромность», «Конформность» (с отрицательным значением) и «Безопасность» (табл. 2).

Таблица 2.

Связь (зависимость) компонента «Ответственность за экологию» субъективного экологического благополучия и ценностей личности $(\mathrm{N}=138)$.

\begin{tabular}{|l|l|l|lll|}
\hline Компонент & Ценность & $\mathrm{b}^{*}$ & Мотивационная цель \\
\hline & Гедонизм &, 233 & $\begin{array}{l}\text { Стремление к } \\
\text { чувственному }\end{array}$ & \\
\hline
\end{tabular}




\begin{tabular}{|c|c|c|c|}
\hline \multirow{5}{*}{$\begin{array}{l}\text { природу } \\
\text { регионе } \\
\text { проживания }\end{array}$} & & & удовлетворению \\
\hline & Безопасность & ,295 & $\begin{array}{l}\text { Безопасность и } \\
\text { общества в целом }\end{array}$ \\
\hline & Скромность & ,229 & $\begin{array}{l}\text { Признание незначительности } \\
\text { существования одного человека в } \\
\text { круговороте жизни }\end{array}$ \\
\hline & Конформность &,- 290 & $\begin{array}{l}\text { Соблюдение правил, законов и } \\
\text { формальных обязательств } \\
\text { Избегание причинения вреда или } \\
\text { огорчения другим людям }\end{array}$ \\
\hline & Традиция & ,314 & $\begin{array}{l}\text { Поддержание } \\
\text { культурных, } \\
\text { религиозных традиций }\end{array}$ \\
\hline
\end{tabular}

Примечание: * - коэффициент регрессии, «0» в значениях перед запятой опущены.

Исходя из полученных данных, можно заключить, что возложение ответственности за экологию и природу на официальные органы и структуры, уход от личной ответственности может быть обусловлен, с одной стороны, признанием «незначительности существования одного человека в круговороте жизни», стремлением к удовольствию и чувственному удовлетворению, а с другой стороны, значимостью поддержания и сохранения культурных, семейных или религиозных традиций, стремлением (или декларированием этого стремления) к безопасности и стабильности общества в целом, что может быть достигнуто только через социальные институты, а человек здесь «сам по себе» и не обязан стремиться соблюдать «правила, законы и формальные обязательства».

Третий компонент субъективного экологического благополучия «Значимость и оценка информированности» определили высокая значимость и 
степень информированности об экологической ситуации в районе проживания, в области $(0,736)$, в стране и мире, и при этом готовность к переезду на другое место жительства.

Данный компонент обусловлен такими базовыми ценностями, как «Благожелательность. Забота», «Скромность», «Власть. Ресурсы» (табл. 3).

Таблица 3.

Связь (зависимость) компонента «Значимость и оценка информированности» субъективного экологического благополучия и ценностей личности $(\mathrm{N}=138)$.

\begin{tabular}{|c|c|c|c|}
\hline Компонент & Ценность & $b^{*}$ & Мотивационная цель \\
\hline \multirow[t]{3}{*}{$\begin{array}{l}\text { Значимость и } \\
\text { оценка } \\
\text { информированности } \\
\text { об экологии }\end{array}$} & Скромность & ,210 & $\begin{array}{l}\text { Признание } \\
\text { незначительности } \\
\text { существования } \\
\text { человека в одного } \\
\text { жизни }\end{array}$ \\
\hline & Власть. Ресурсы & ,263 & $\begin{array}{l}\text { Влияние посредством } \\
\text { контролирования } \\
\text { материальных и социальных } \\
\text { ресурсов }\end{array}$ \\
\hline & $\begin{array}{l}\text { Благожелательность } \\
\text { — Забота }\end{array}$ & 280 & $\begin{array}{l}\text { Преданность группе } \\
\text { благополучие ее членов }\end{array}$ \\
\hline
\end{tabular}

Примечание: * - коэффициент регрессии, «0» в значениях перед запятой опущены.

Согласно данным, предикторами значимости информированности об экологических проблемах выступают такие социальные цели, как преданность группе и благополучие ее членов, влияние посредством контролирования материальных и социальных ресурсов, что дает человеку информация в целом, 
но также и скромность, как ценность признания незначительности существования одного человека в общем потоке информации.

Четвертый компонент субъективного экологического благополучия обозначен, как «Значимость природьл и связь с природой» и его составили значимость частоты отдыха на природе как самого человека, так и членов семьи, и окружающих, а также высокая степень желания бывать на природе. Также данный компонент субъективного экологического благополучия объединил описание активных действий в природной среде, активное взаимодействие с ней и, согласно шкале «Единение с природой» соответствует фактору «Активность».

Указанный компонент связан с ценностями «Благожелательность. Забота», «Традиция» (отрицательное значение) и «Универсализм. Природа» (табл. 4).

Определяющими целями, связанными со значимостью природы для человека, являются сохранение природной среды, преданность группе и благополучие ее членов, что, по-видимому, объясняет потребность активного отдыха на природе в кругу близких людей. Но при этом отрицательные значения связи с ценностью «Традиция» могут свидетельствовать о том, что у большей части людей «отдых на природе» не является частым проведением досуга.

Таблица 4.

Связь (зависимость) компонента «Значимость природы и связь с природой» субъективного экологического благополучия и ценностей личности $(\mathrm{N}=138)$.

\begin{tabular}{|c|c|c|c|}
\hline Компонент & Ценность & $b^{*}$ & Мотивационная цель \\
\hline $\begin{array}{l}\text { Значимость } \\
\text { природы, }\end{array}$ & Традиция &,- 242 & $\begin{array}{l}\text { Поддержание и сохранение } \\
\text { культурных, семейных } \\
\text { религиозных традиций }\end{array}$ \\
\hline связь & Универсализм. & , 198 & Сохранение природной среды \\
\hline
\end{tabular}




\begin{tabular}{|l|l|l|lc|}
\hline природой & Природа & & \\
\cline { 2 - 5 } & $\begin{array}{l}\text { Благожелательность } \\
\text { - Забота }\end{array}$ & & $\begin{array}{l}\text { Преданность группе } \\
\text { благополучие ее членов }\end{array}$ \\
\hline
\end{tabular}

Примечание: * - коэффициент регрессии, «0» в значениях перед запятой опущены.

Пятый компонент субъективного экологического благополучия «Значимость экологических проблем» определяется частотой обсуждения экологических вопросов с членами семьи, родственниками, друзьями, соседями, коллегами по работе. Ценностные предикторы «Благожелательность. Забота» (отрицательное значение коэффициента), «Универсализм. Природа» и «Самостоятельность мыслей».

Таблица 5.

Связь (зависимость) компонента «Значимость экологических проблем» субъективного экологического благополучия и ценностей личности ( $\mathrm{N}=138)$.

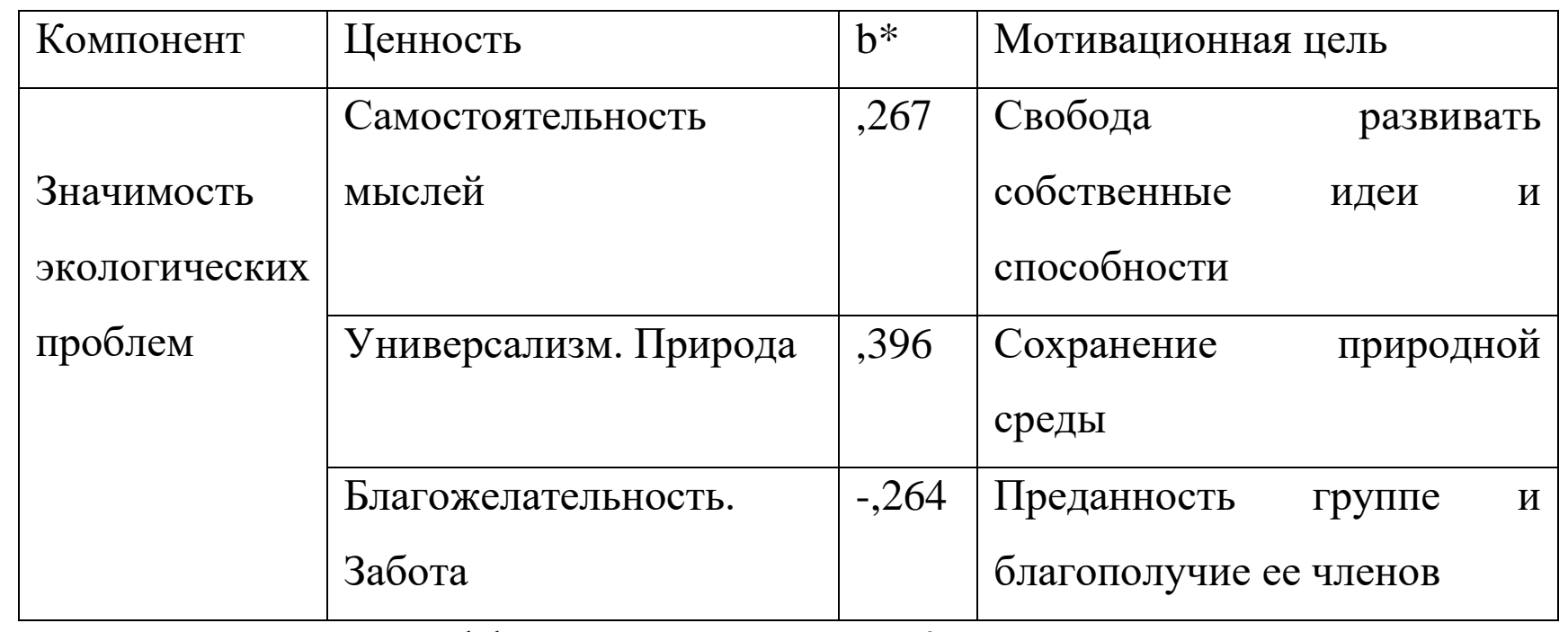

Примечание: * - коэффициент регрессии, «0» в значениях перед запятой опущены.

Согласно полученным данным, частота обсуждения человеком экологических вопросов с близкими людьми и коллегами по работе характеризует значимость для личности проблем, связанных с экологией и природой. Определяющими целями, в этой связи, закономерно выступают 
сохранение природной среды; свобода развивать собственные идеи и способности, при отказе следовать групповым нормам, несмотря на то что это может повлиять на благополучие ее членов.

Шестой компонент субъективного экологического благополучия личности «Значимость здоровья» характеризуется важностью здоровья и изменения его состояния в связи с экологической ситуацией в районе проживания, ожиданиями изменения здоровья в ближайшем будущем, частотой обращения за медицинской помощью, а также принятием на себя ответственности за состояние окружающей природной среды.

Определяющие данный компонент субъективного экологического благополучия личности ценности «Самостоятельность» $(0,354)$, «Скромность» и «Репутация» (отрицательное значение коэффициента) (табл. 6).

Таблица 6.

Связь (зависимость) компонента «Значимость здоровья» и ценностей личности $(\mathrm{N}=138)$.

\begin{tabular}{|c|c|c|c|}
\hline Компонент & Ценность & $b^{*}$ & Мотивационная цель \\
\hline \multirow{3}{*}{$\begin{array}{l}\text { Значимость } \\
\text { Здоровья }\end{array}$} & Самостоятельность & ,355 & $\begin{array}{l}\text { Свобода развивать собственные идеи и } \\
\text { способности, определять собственные } \\
\text { действия }\end{array}$ \\
\hline & Скромность & ,213 & $\begin{array}{l}\text { Признание } \\
\text { существования одного человека в } \\
\text { круговороте жизни }\end{array}$ \\
\hline & Репутация & - 305 & $\begin{array}{l}\text { Защита и влияние посредством } \\
\text { поддержания публичного имиджа и } \\
\text { избегания унижения }\end{array}$ \\
\hline
\end{tabular}

Примечание: * - коэффициент регрессии, «0» в значениях перед запятой опущены.

Исходя из имеющихся данных, можно заключить, что значимость здоровья для человека связана со стремлением быть самостоятельным - 
свободой развивать собственные идеи и способности, и в то же время признанием незначительности существования одного человека в круговороте жизни, т.е. скромностью. Можно предположить, что значимость этих ценностей определяют действия и поступки человека в ситуациях, когда возникают трудности, болезни и т.П. При этом в случаях возникновения проблем здоровья для человека становится маловажным публичный имидж, избегание через защиту и влияние.

Седьмой компонент субъективного экологического благополучия личности, обозначенный нами как «Ответственность за здоровье других людей», в первую очередь родных и близких. Он определяется, с одной стороны, значимостью здоровья и беспокойством за здоровье членов семьи; психологической готовностью к смене места жительства из-за неблагоприятности экологических условий жизни и их влияния на собственное здоровье и здоровье близких людей. С другой стороны, повышением степени привязанности к региону проживания, значимостью «малой Родины» для человека; предположением, что при переезде на другое место жительства физическое самочувствие лучше не станет; надеждой на позитивные изменения экологических условий; определенной активной позицией, направленной на различные действия по улучшению экологических условий своей жизни.

Основные ценностные предикторы данного компонента «Самостоятельность мыслей», «Универсализм. Толерантность», «Универсализм. Забота о других», «Безопасность Общественная» (две последние ценности с отрицательным значением коэффициента) (табл.7).

Таблица 7.

Связь (зависимость) компонента «Ответственность за здоровье других людей» субъективного экологического благополучия и ценностей личности ( $\mathrm{N}=$ 138).

\begin{tabular}{|l|l|l|l|}
\hline Компонент & Ценность & $\mathrm{b}^{*}$ & Мотивационная цель \\
\hline & Самостоятельность &, 405 & Свобода развивать собственные \\
\hline
\end{tabular}




\begin{tabular}{|l|l|l|l|}
\hline \multirow{2}{*}{$\begin{array}{l}\text { Ответственность } \\
\text { за здоровье }\end{array}$} & мыслей & & идеи и способности \\
\cline { 2 - 5 } $\begin{array}{l}\text { других (родных } \\
\text { илизких) }\end{array}$ & $\begin{array}{l}\text { Универсализм. } \\
\text { Забота о других }\end{array}$ &,- 265 & $\begin{array}{l}\text { Стремление к равенству, } \\
\text { справедливости и защите всех } \\
\text { людей }\end{array}$ \\
\cline { 2 - 4 } & $\begin{array}{l}\text { Универсализм. } \\
\text { Толерантность }\end{array}$ &, 285 & $\begin{array}{l}\text { Принятие и понимание тех, кто } \\
\text { отличается от тебя }\end{array}$ \\
\cline { 2 - 4 } & $\begin{array}{l}\text { Безопасность. } \\
\text { Общественная }\end{array}$ &,- 292 & $\begin{array}{l}\text { Безопасность и стабильность } \\
\text { общества в целом }\end{array}$ \\
\hline
\end{tabular}

Примечание: * - коэффициент регрессии, «0» в значениях перед запятой опущены.

Согласно полученным результатам, данный компонент субъективного экологического благополучия личности связан со стремлением человека развивать собственные идеи и способности, принимать и понимать тех, кто отличается от тебя, что согласуется с готовностью принимать активные действия ради здоровья и благополучия родных и близких. Но при этом «круг» людей, за которых человек беспокоится и готов нести ответственность ограничивается именно близкими людьми. Цель безопасности и стабильности общества в целом, а также справедливости и защите всех людей, в данном случае не ставится.

Обобщая полученные результаты, можно заключить, что субъективное экологическое благополучие личности связано с рядом индивидуальных базовых ценностей личности. Основными ценностями, определяющими субъективное экологическое благополучие личности выступают «Благожелательность. Забота», «Скромность», «Универсализм» - забота о природе и толерантность к другим людям, «Свобода мыслей», «Самостоятельность», «Гедонизм», «Традиция» «Конформность», «Безопасность», «Власть. Ресурсы», «Репутация». Эти ценности, при объединении их в ценности высшего порядка (по Ш. Шварцу) свидетельствуют о том, что предикторами субъективного экологического благополучия выступает как «Самопреодоление» - преодоление личных 
интересов ради других, так и «Самоутверждение» - стремление к удовлетворению собственных интересов; как «Открытость изменениям» готовность к новым или преобразующим идеям, действиям и переживаниям, так и ценности «Сохранения» - избегание изменений, самоограничение и порядок. Вместе с тем, если рассмотреть выделенные ценностные предикторы с позиции пар метаценностей (по Ш.Шварцу), то можно сказать, что субъективное экологическое благополучие личности в большей степени зависит от ценностей, имеющих социальную направленность, они связаны с другими людьми и устоявшимися институтами, выражают интересы группы. Данный факт, на наш взгляд, можно объяснить тем, что экологические проблемы в большей степени остаются проблемами социальными. Но при этом, «личностный фокус» метаценностей, выражающий интересы индивида, имеющий личную направленность также определяет субъективное экологическое благополучие.

\section{Литература:}

1. Панов В.И., Мдивани М.О., Кодесс П.Б., Лидская Э.В., Хисамбеев Ш.Р. Экологическое сознание: теория, методология, диагностика // Психологическая диагностика. 2012. № 1. С. 3-126.

2. Хащенко В.А. Личность и группа в системе экономических и управленческих отношений. М.: Изд-во «Институт психологии РАН», 2016. 3. Хащенко Н.Н., Баранова А.В., Панова Е.M., Смирнова Н.П. Экологическое благополучие как компонент ценностного сознания личности: программа исследования // Экопсихологические исследования-6: экология детства и психология устойчивого развития: сборник научных статей / Отв. ред. В.И. Панов. - М.: ФГБНУ «Психологический институт РАО»; Курск: Университетская книга, 2020. С. 81-85.

4. Шварц Ш., Бутенко Т.П., Седова Д.С., Липатова А.С. Уточненная теория базовых индивидуальных ценностей: применение в России / Журнал Высшей школы экономики. Психология. 2012. Т. 9, № 1. С. 43-70. 


\section{References:}

1. Panov V.I., Mdivani M.O., Kodess P.B., Lidskaya E.V., Hisambeev Sh.R. Ekologicheskoe soznanie: teoriya, metodologiya, diagnostika // Psihologicheskaya diagnostika. 2012. № 1. S. 3-126.

2. Hashchenko V.A. Lichnost' i gruppa $\mathrm{v}$ sisteme ekonomicheskih i upravlencheskih otnoshenij. M.: Izd-vo «Institut psihologii RAN», 2016.

3. Hashchenko N.N., Baranova A.V., Panova E.M., Smirnova N.P. Ekologicheskoe blagopoluchie kak komponent cennostnogo soznaniya lichnosti: programma issledovaniya // Ekopsihologicheskie issledovaniya-6: ekologiya detstva i psihologiya ustojchivogo razvitiya: sbornik nauchnyh statej / Otv. red. V.I. Panov. M.: FGBNU «Psihologicheskij institut RAO»; Kursk: Universitetskaya kniga, 2020. S. 81-85.

4. Shvarc SH., Butenko T.P., Sedova D.S., Lipatova A.S. Utochnennaya teoriya bazovyh individual'nyh cennostej: primenenie v Rossii / ZHurnal Vysshej shkoly ekonomiki. Psihologiya. 2012. T. 9, № 1. S. 43-70. 